\title{
Decreased glutamate dehydrogenase protein in spinocerebellar degeneration
}

\author{
K KAJIYAMA, S UENO, T TATSUMI, S YORIFUJI, M TAKAHASHI, S TARUI \\ From the Second Department of Internal Medicine, Osaka University Medical School, Osaka, Japan
}

SUMMARY A radioimmunoassay system for determining content of glutamate dehydrogenase $(\mathrm{GDH})$ in human leukocytes was established and studied in 14 patients with spinocerebellar ataxia or atypical Parkinsonism. The protein content of leukocyte GDH was decreased in four patients and the reduction in the protein content was proportional to that in the enzyme activity. The ratio of GDH activity to protein content was invariable in healthy controls, diseased controls and patients with reduced GDH activity. These results suggested that at least a portion of the partial GDH deficiency was due to the decreased level of the enzyme protein.

Spinocerebellar degeneration is a heterogeneous disease complex, and the majority of the diseases have not been characterised biochemically. Recently, several authors have reported the partial deficiency in glutamate dehydrogenase (GDH; EC 1.4.1.3) activity in leukocytes, fibroblasts, platelets and muscles from patients with nondominant or dominant form of olivopontocerebellar atrophy (OPCA). ${ }^{1-5}$ These findings suggested that systemic abnormality of glutamate metabolism might be related to a subgroup of OPCA. However, it remains unclear whether or not GDH deficiency is aetiologically significant, and little is known about the mechanism by which GDH activity is reduced.

In this study, we established a radioimmunoassay for determination of GDH protein content in human leukocytes and studied patients with spinocerebellar ataxia.

\section{Materials and methods}

Fourteen patients with spinocerebellar degeneration or atypical Parkinsonism and eight age-matched, healthy controls were studied. Four patients who showed significantly lower level of GDH activity than controls are presented below. No members with similar diseases were known in the families of each case.

Patient I A 31 year old man had unsteady gait and

Address for reprint requests: Dr Koji Kajiyama, The Second Department of Internal Medicine, Osaka University Medical School, 1-1-50 Fukushima, Fukushima-ku, Osaka 553, Japan.

Received 5 January 1988 and in revised form 5 April 1988. Accepted 11 April 1988 difficulty in speech since the age of 26 . He had tonic pupils and downbeat nystagmus on primary position and on lateral gaze. The muscle stretch reflexes were hyperactive. The plantar responses were flexor. Marked dysmetria and terminal tremor were observed on finger-to-nose and heel-toshin tests. His gait was wide-based and ataxic. Computed tomography (CT) and magnetic resonance imaging (MRI) revealed cerebellar atrophy.

Patient 2 A 60 year old man had a 10 year history of progressive gait disturbance. His parents were first cousins. Neurological examination revealed reduced movements of the soft palate and hyperactive tendon reflexes. Coordination was markedly impaired with dysmetria, dysdiadochokinesia and terminal tremor. Light touch sensation and pinprick sensibility were impaired in glove and stocking distribution. Electromyogram revealed high amplitude and polyphasic motor unit potentials in the lower extremities, with normal conduction velocities of motor and sensory nerves. CT showed cerebellar atrophy.

Patient 3 A 56 year old man noted difficulty in hand movements when aged 41 years, and began to have marked difficulty in walking and speech later. He had horizontal nystagmus on lateral gaze, severe ataxia of extremities and decreased vibration sensation in the legs. Muscle stretch reflexes were decreased throughout. Sensory nerve conduction velocities were decreased. CT and MRI revealed atrophy of cerebellum and brainstem.

Patient 4 A 45 year old man noted dragging of his left leg at age 34 years and gradually developed resting tremor of his left hand fingers. He was diagnosed as juvenile Parkinsonism, and was given levodopa with some improvement. Neurological examination at admission revealed vertical oculomotor dysfunction, bradykinesia, rigidity in extremities, and intermittent dyskinetic movements of his trunk and left arm. Cerebellar signs were not apparent. CT revealed diffuse, atrophic changes of cerebrum and cerebellum. 
Enzyme assay of leukocyte $G D H$

Leukocytes were separated with $6 \%$ dextran from heparinised venous blood, and were disrupted by freeze and thaw cycles. These cells were subjected to enzyme assay and radioimmunoassay. GDH activities were measured fluorometrically by a modification of the method described by Plaitakis et al. ${ }^{2}$ Aliquots of the homogenate were incubated at $47 \cdot 5^{\circ} \mathrm{C}$ for 60 minutes. The activity determined after incubation was considered to represent "heat-stable" GDH. This value was subtracted from the total activity to obtain the activity of "heat-labile" GDH.

\section{Radioimmunoassay of leukocyte GDH protein}

GDH proteins purified from bovine liver, rat liver and bacteria (Proteus species) were purchased from Sigma USA. Rabbits were subcutaneously injected with $1 \mathrm{mg}$ of bovine liver GDH emulsified in Freund's complete adjuvant at 2-week intervals and were bled 7 days after the third injection. The specificity and cross-reactivity of the antiserum was tested by immunoblot analysis with protein extracts from rat cerebellum and liver, and by ELISA using GDH purified from bovine liver, rat liver and bacteria as antigens. Crossreactivity of the antiserum with human GDH was evidenced by its ability of inhibiting GDH activity of human leukocytes. The antiserum thus prepared and examined was used for the radioimmunoassay of GDH protein in leukocytes. The disrupted leukocytes were sonicated in $0.01 \mathrm{M}$ phosphate buffer (pH 7.6) including $0.5 \%$ Triton $\mathrm{X}, 1 \mathrm{mM}$ phenylmethylsulfonyl fluoride and $5 \mathrm{mM}$ EDTA, and centrifuged at $100,000 \mathrm{~g}$ for 30 minutes. To measure the amount of GDH protein in human leukocyte GDH, the supernatant was incubated with the antiserum overnight and then with ${ }^{131} \mathrm{I}-\mathrm{GDH}$ for 30 minutes. The antigen-antibody complexes were precipitated by anti-rabbit gamma globulin serum. After centrifugation, radioactivity of the resulting pellets was counted in a gamma counter. Standard inhibition curve of ${ }^{131}$ I-GDH binding to the antibody was made using native bovine liver GDH as a competitive agent. Apparent protein content of GDH in human leukocytes was estimated by the standard curve.

\section{Results}

GDH activity in human leukocytes Mean GDH activity in eight healthy controls was 0.46 , SD 0.05 $\mathrm{mmol} \mathrm{NAD} / \mathrm{g}$ protein/h (table). The lowest value was 0.36 , the highest 0.51 . Similar values were found in 10 patients with spinocerebellar degeneration or atypical Parkinsonism (range, 0.40 to 0.60 ). We called these patients diseased controls. Values below the lowest of the eight healthy controls were found in leukocytes from Patients 1,2,3, and 4. The values of GDH activity in these four patients was 0.26 , SD $0.04 \mathrm{mmol}$ $\mathrm{NAD} / \mathrm{g}$ protein $/ \mathrm{h}$. The lowest value was 0.20 , the highest $0 \cdot 29$. The values of these patients were significantly lower ( 2 SD below the healthy control mean, $p<0.001$ ) and we regarded these four patients as having partial GDH deficiency.

Radioimmunoassay for leukocyte GDH content Immunoblot analysis revealed a single reactive protein with a molecular weight of 55,000 dalton in rat cerebellar and liver extracts. The antiserum crossreacted with rat liver $(30 \%)$ and bacteria $(5 \%)$ GDH in ELISA and inhibited the GDH activity of the human leukocyte extract by $30 \%$. The competitive inhibition curve made with leukocyte extract showed a similar profile to that made with bovine GDH, which enabled us to deduce apparent GDH contents in leukocyte extracts (fig). There were no significant differences in apparent protein contents between healthy controls and diseased controls. The level of GDH protein content in leukocyte from the patients with reduced enzyme activity was about $50 \%$ of the control value. The ratio of GDH activity to apparent GDH protein content was similar level (about 15 $\mathrm{mmol} \mathrm{NAD} / \mathrm{g} \mathrm{GDH} / \mathrm{min}$ ) in healthy controls, diseased controls and patients with reduced GDH activity (table).

\section{Discussion}

The four patients with reduced GDH activity had various clinical manifestations. Three of them (Patients 1, 2, 3) manifested progressive cerebellar dysfunction without affected members in their families. These three patients had involvements of other nervous systems including corticospinal, oculomotor dysfunction and peripheral neuropathy. The remaining case (Patient 4) was similar to the cases reported by Duvoisin $\mathrm{et}^{\mathbf{3}}$ in that the extrapyramidal

Table GDH activity and protein content in leukocytes

\begin{tabular}{|c|c|c|c|c|}
\hline & \multirow[b]{2}{*}{ Total } & \multicolumn{2}{|l|}{ Activity } & \multirow[b]{2}{*}{$\begin{array}{l}\text { Activity/ } \\
\text { Protein }\end{array}$} \\
\hline & & $\begin{array}{l}\text { Heat Stable } \\
\text { Heat Labile }\end{array}$ & $\begin{array}{l}\text { Protein } \\
\text { content }\end{array}$ & \\
\hline $\begin{array}{l}\text { Healthy controls } \\
(\mathrm{n}=8)\end{array}$ & $0.46,0.05$ & \multirow{3}{*}{$\begin{array}{l}0 \cdot 30,0 \cdot 04 \\
0 \cdot 16,0 \cdot 04 \\
0 \cdot 30,0 \cdot 09 \\
0 \cdot 21,0 \cdot 06 \\
0 \cdot 20,0 \cdot 02 \dagger \\
0 \cdot 07,0 \cdot 04 \dagger\end{array}$} & $0 \cdot 60,0 \cdot 15$ & $13 \cdot 67,2 \cdot 82$ \\
\hline $\begin{array}{l}\text { Diseased controls } \\
(\mathrm{n}=10)\end{array}$ & $0.51,0.07$ & & $0.56,0.09$ & $15 \cdot 40,2 \cdot 03$ \\
\hline $\begin{array}{l}\text { Partial GDH } \\
\text { Deficiency }(n=4)\end{array}$ & $0 \cdot 26,0.04^{*}$ & & $0.28,0.05 \dagger$ & $15 \cdot 76,1 \cdot 30$ \\
\hline
\end{tabular}

$\overline{\mathrm{GDH}}$ activity, protein content and ratio are expressed in mmol NAD/g protein/h, $\mathrm{mg} \mathrm{GDH} / \mathrm{g}$ protein and $\mathrm{mmol} \mathrm{NAD} / \mathrm{g} \mathrm{GDH} / \mathrm{min}$, respectively. The values quoted are mean, $S D$.

Note: Protein contents are apparent values estimated by the standard inhibition curve made with bovine liver GDH as shown in the figure. Significantly lower than healthy control levels: ${ }^{*} p<0.001,+p<0.02$. 
1080

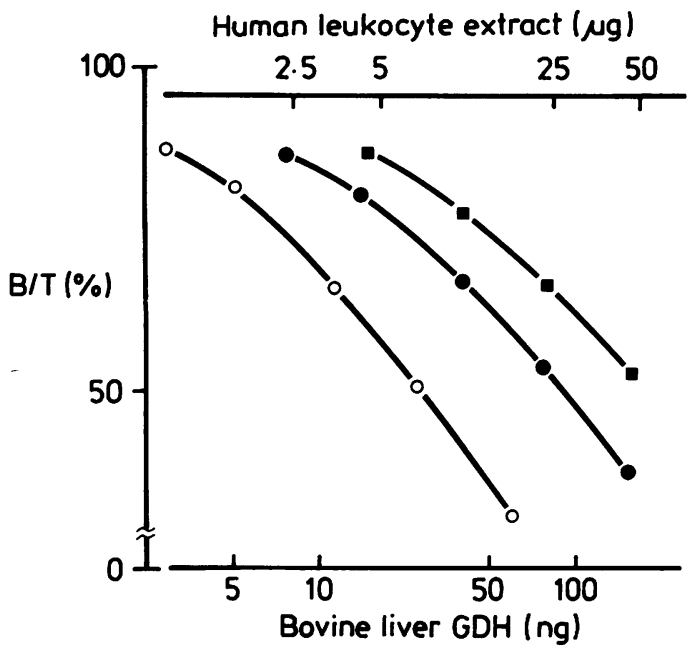

Fig Competitive inhibition curve: competitive inhibition curves by native bovine GDH (open circles), and by leukocyte extracts from healthy control (closed circles) or partial GDH deficiency (closed squares). B/T(\%) indicates percent ${ }^{131} I-G D H$ binding to the antibody / total ${ }^{131} I-G D H$.

features of Parkinsonism overshadowed the cerebellar signs.

Several workers have reported GDH deficiency (30-50\% of control level) in patients with OPCA..$^{1-5}$ Plaitakis et al fractionated leukocyte GDH into "particulate heat-labile" and "soluble heat-stable" components, and reported that the former component was decreased in the GDH deficiency. Our results in enzyme assay were compatible with their results; GDH activities were partially reduced (about $50 \%$ of control level), and the enzyme assay showed that "heat-labile" component was predominantly reduced.

To our knowledge, no attempts have been made to determine the protein level of GDH in leukocytes with partial GDH deficiency. The data from immunoblot analysis, ELISA, and enzyme inhibition assay proved that the antiserum prepared here was highly specific to GDH and recognised the common antigenic sites conserved among different species. These facts attested the availability of anti-bovine GDH serum for determining GDH contents in human leukocytes. The radioimmunoassay system we established here was sensitive enough to detect $100 \mathrm{fmol}$ of $\mathrm{GDH} / \mathrm{ml}$
Kaiịama, Ueno, Tatsumi, Yorifuii, Takahashi, Tarui

leukocyte extract, which made it possible to determine the GDH content in leukocytes obtained from only $3 \mathrm{ml}$ peripheral blood. Using this technique, we demonstrated the reduction in GDH protein content of leukocytes from the patients with reduced GDH activity, and showed that the reduction of the enzyme protein was proportional to that of the enzyme activity. The ratio of GDH enzyme activity to GDH protein content in leukocytes was invariable in healthy controls, diseased controls and patients with reduced GDH activity. The plausible explanation is that partial deficiency of GDH, at least in our cases, is due to decreased level of GDH protein, not to the structural variation leading to the qualitative changes. This hypothesis may be in part supported by observation made by Plaitakis et al, ${ }^{1}$ that there were no differences in apparent $\mathrm{Km}$ and in the regulatory effect of nucleotides between the GDH deficiency and normal controls.

The GDH deficiency and its aetiological significance were not confirmed in spinocerebellar degeneration. Additional studies of this enzyme should be made to confirm the specific, metabolic abnormality in that condition.

This investigation was supported by a grant funded by the Ministry of Education, Science and Culture (Project 61570386), Japan.

\section{References}

I Plaitakis A, Nicklas WJ, Desnick RJ. Glutamate dehydrogenase deficiency in three patients with spinocerebellar syndrome. Ann Neurol 1980;7:297-303.

2 Plaitakis A, Berl S, Yahr MD. Neurological disorders associated with deficiency of glutamate dehydrogenase. Ann Neurol 1984;15:144-53.

3 Duvoisin RC, Chokroverty S, Lepore F, Nicklas W. Glutamate dehydrogenase deficiency in patients with olivopontocerebellar atrophy. Neurology 1983;33: 1322-6.

4 Sorbi S, Tonini S, Giannini E, Piacentini S, Marini P, Amaducci L. Abnormal platelet glutamate dehydrogenase activity and activation in dominant and nondominant olivopontocerebellar atrophy. Ann Neurol 1986;19:239-45.

5 Finocchiaro G, Taroni F, DiDonato S. Glutamate dehydrogenase in olivopontocerebellar atrophies: Leukocytes, fibroblasts, and muscle mitochondria. Neurology 1986;36:550-3. 